\title{
SMART WORKING AND ONLINE PSYCHOLOGICAL SUPPORT DURING THE COVID-19 PANDEMIC: WORK-FAMILY BALANCE, WELL-BEING, AND PERFORMANCE
}

\author{
Sebastiano Rapisarda ${ }^{1}$, Elena Ghersetti ${ }^{2}$, Damiano Girardi ${ }^{3}$, Nicola Alberto De Carlo ${ }^{1,3}$, \\ \& Laura Dal Corso ${ }^{3}$ \\ ${ }^{1}$ LUMSA University of Rome (Italy) \\ ${ }^{2}$ PSIOP, Institute of Psychotherapy and Intervention on Organizational Disease of Padua (Italy) \\ ${ }^{3}$ University of Padua (Italy)
}

\begin{abstract}
During lockdown and the severe restrictions aimed to combat the COVID-19 pandemic, in Italy great consideration has been given to "smart working" (SW). This term refers to a form of work characterized by the absence of time or space restrictions and an organization by phases, cycles, and objectives. The requirements for SW are: work must be carried out electronically; the tools must be adequate; performance must be measurable and focused on objectives; employees must have a suitable place to get their work done. These requirements ensure that the essential objectives of SW are attained: replacing the logic of performing tasks with that of achieving objectives; allowing everyone to manage work actively and autonomously; stimulating more decisive accountability in work, and better performance.

Since the COVID-19 outbreak, action-research interventions have been conducted by private and public organizations. The private sector has endeavored to meet the requirements described above. This has not always been the case in the public sector, where largely widespread and indiscriminate use of SW has been made, not always complying with the protocols. However, even within the "emergency" limits of these experiences, SW has generally been accepted. The main advantages reported by employees are time and money saved on travel and food, in addition to improved family life. However, some problems have also emerged. These include the perception of social isolation; difficulty in disconnecting from technology; inadequacy of the tools; inadequate communication with managers. We also found that the health conditions of some "smart workers" have worsened in terms of anxiety, sleep disorders, and emotional symptoms.

The data clearly show the complexity of analyses and interventions in relation to the SW phenomenon. The protection of employees' health, especially in terms of recovery and work-family balance, appears to be particularly complex. In this context, the authors' experience shows that online psychology has become more significant because it allows to support employees at any time. The literature highlights the growing use of online psychological support also through smartphone apps that provide effective interventions anywhere.

Therefore, if, on the one hand, the requirements, objectives, and good practices of SW are to be pursued to limit the critical issues that have arisen, on the other, organizations should provide psychological support to employees even at a distance and by using appropriate technologies.
\end{abstract}

Keywords: Smart working, online psychological support, work-family balance, well-being, performance.

\section{Introduction}

Since its initial emergence in the city of Wuhan in late 2019, the COVID-19 disease has drastically altered social structures around the world. At the end of March 2021, according to a recent situation report by the World Health Organization, the number of global COVID-19 cases has grown to nearly 127 million, with over 2.5 million deaths. In Italy the confirmed cases are around 3.5 million, with nearly 105.000 deaths (World Health Organization, 2021). A fast surge of contagions was testified in Italy already at the beginning of March 2020, a few weeks after the first case of COVID-19. Italy has rapidly become the country hit second hardest by the coronavirus in the world. The first line of defense against this pandemic has been reducing physical interaction. The Italian government established a national lockdown that allowed people to leave their houses only for proven work, health, or extreme necessities. This has forced most companies, public and private, to make use of smart working. 


\subsection{Smart working}

Smart working - SW - is a label used to describe a new attitude to work and the workplace. This is a mode of subordinate employment relationship characterized by the absence of time or spatial restrictions and an organization by phases, cycles, and objectives, established by an agreement between employee and employer; a mode that helps the employee to reconcile life and work and, at the same time, favors the growth of productivity. The definition of SW, contained in Law nr. 81/2017, emphasizes organizational flexibility, the voluntary nature of the individual agreement signed by the parties, and the use of tools that allow employees to work remotely.

SW is not a new form of corporate welfare, nor can it be confused with the simple practice of working from home once a week. It is a multidisciplinary approach centered on four necessary and fundamental requirements (De Carlo \& Maccani, 2021).

1. Nature of the work: carried out by computer and online.

2. Technology: PC and good remote connection to the management network and organization data sets.

3. Relationship structure: no longer time-based but achievement-based performance measurable and accountable.

4. Logistics: a suitable place to carry out one's work.

They relate to the essential objectives of SW:

- $\quad$ supporting and replacing the logic of performing tasks with that of achieving the goals set by the organization and shared with the employee. This is achieved through experiments to be carried out on staff quotas that increase over time, to enhance the efficiency/effectiveness of the services provided;

- allowing everyone, according to their skills and abilities, to manage content and work situations more actively, performing functions characterized by increasing working autonomy. As it is shown in the specialist literature, one of the main components of job satisfaction is autonomy in operations, feeling fully involved in the results achieved. Autonomy is also manifested in the employee being able to operate at the preferred time and in the preferred environment, thus obtaining a more reasonable work-family balance;

- SW, according to Law nr. 81/2017, was conceived as an important impulse to more decisive accountability in the work activity, with better results expected by organizations in terms of individual and collective productivity, and therefore higher performance. It must protect employee's health, while increasing organizational well-being. These two dimensions are essential constituents of good work, satisfaction, and the consequent increase in the quality of products/services provided.

During lockdown and while restrictions were "intermittently" in place in the time of Covid-19, considerable relevance has been given to SW, with the common and decisive objective of protecting employees' health.

\subsection{Online psychology}

Computer-based technologies play a growing and central role in our society and are promising ways to work and care in the psychological field. In the organizational context, much scientific evidence demonstrates how new technologies play an important role in achieving individual and collective well-being. The COVID-19 pandemic has further changed the working methods, the way of communicating and socializing, causing fast significant changes for the entire community, with daily online work being the norm for many people (Li et al., 2020).

The psychologist also takes part in this change, by providing psychological services directly online. When referring to psychological performance, we mean a "professional action which, through the relationship, is aimed to produce an evaluation or to promote a change/improvement based on the needs, expectations, questions expressed by the client" (Bozzaotra et al., 2017, p. 41). When this is made available online, the web and new communication technologies play an auxiliary role: as the tool through which the psychologist and the user interface.

In Italy, the number of services linked to online psychological interventions is increasing. The use of these intervention methods presents several advantages, first of all, the removal of barriers: architectural, for people with disabilities; linked to stigmas, in terms of the prejudices that often hinder access to psychological interventions. Furthermore, they allow a continuity of relationship with traditional in vivo interventions: professionals can remain in contact with their clients even when not sharing the same territory. Finally, from the point of view of research, these methodologies play a fundamental role, appearing as an interesting sector of innovation (Richardson \& Simpson, 2015). 


\section{New labor codes}

Rationality must be constantly pursued, both in the concrete aspects, for example, with regard to SW, considering the presence of the four requirements described above, and in terms of the reference framework, i.e., harmonization and integration of SW with the essential objectives that must characterize it. This takes place in a framework of good practices, to be shared with employees.

\subsection{Organizational well-being and work-related stress}

As already mentioned, organizational well-being plays an important role in the productivity of the company and is one side of the coin while the prevention of work-related stress is the other. Constant and adequate management of stress factors is needed by both the organization and individuals, to allow employees to respond appropriately to the challenges of the work environment. Likewise, individual resources, such as a sense of self-efficacy, resilience, and optimism, as well as effective coping strategies including time management, the use of cognitive skills and logic, the ability to regenerate one's physical and emotional energies, are important (Dal Corso et al, 2020; De Carlo et al., 2013; Di Sipio et al., 2012).

\subsection{Positive management}

The organizational interventions outlined above are placed in the perspective of positive management. This is achieved through managerial behavior aimed to enhance people and their energies. Therefore, organizations need adequate training and involvement with their management. Some of the main dimensions on which each manager is called to reflect and operate are outlined below (De Carlo et al., 2020; Dimitrova, 2019; Donaldson-Feilder et al, 2011).

- Management of emotions, personal equity, and integrity: behaving coherently and respectfully toward the staff, without harboring excesses and unstable, contradictory attitudes; being attentive, empathetic, and caring with collaborators.

- Realistic planning and management of work: clearly expressing and disseminating objectives, organizing and distributing everyone's commitments in a balanced way; implementing, also through group meetings and personal interviews, adequate monitoring of workloads, alignment with priorities, and ongoing activities.

- Management of difficult situations and conflicts: acting as mediators, with patience, in a perspective of transformational leadership, aimed to enhance and change principles and values, as well as working behavior; consulting the collaborators to prevent any further difficulties.

- Management of the individual collaborator: having constructive relationships with each person, through meetings, individualized interviews, friendly and cordial relationships, socialization events.

\subsection{Work-family balance}

The construct of conflict between work and family has its origins in role theory and is defined as a form of inter-role conflict in which the pressures from the domain of work and that of the family are mutually incompatible. This is a two-way construct: there can be interference from work to the family and vice versa. The role of organizations in supporting reconciliation between work and family life is significant. Work-family support is defined as discretionary and formal organizational policies, services, and benefits aimed to reduce employees' work-family conflict and/or support their family roles outside of the workplace (Masterson et al., 2020). In this regard, organizations can implement a work-family culture, characterized by shared assumptions relating to the organization's tendency to support integration between work and family life. The presence of a supportive culture seems to be necessary for the policies supporting reconciliation to be positively accepted by employees (Argentero \& Cortese, 2021; De Carlo et al., 2019).

\section{Action research methodology and empirical experiences}

Action research is a "participatory democratic" process to increase theoretical and practical knowledge as well as to respond to requests for greater participation from all stakeholders. It is a research approach through which we try to build, together with all the staff of the organization, action and reflection, theory and practice, to find concrete solutions to critical issues and actively change and improve processes within the organization itself (Kaneklin et al., 2010; Lewin, 1946; Reason \& Bradbury, 2001). 
In the last year, we collected qualitative judgments on the opportunities and limits of SW in time of Covid-19. These judgments collected by psychologists operating in the organizational field for public and private companies of the health and education sectors, based on their direct knowledge, through observation and interviews, of what the employees experienced. It was found that in the private sector SW was used if the requirements previously indicated at points 1 and 2 were present. Instead, in the public sector, no reference was made to the aforementioned requirements and there was a generalized and indiscriminate use of SW, which in many cases coincided with the drastic reduction or even the closure of most of the activities. Moreover, due to the emergency the country was facing, both sectors could not always take into account the main objectives of SW, as summarized above. In general, the complete set of requirements and objectives of $\mathrm{SW}$, which must be closely integrated, is not yet part of the common experience.

The advantages that emerged from the interviews are listed below as reported by the employees:

"lower expense for gasoline and parking"

"presence of the family - more time at home with the family"

"reduction of working time due to the home-workplace commute"

As can be noted, the advantages include saving time and money for travel, parking, and food, as well as the expansion of the sphere of family life given that most people have carried out their work activities from home. However, a number of critical issues also emerged that led to the need to offer employees greater support for the future. Among these issues, some are listed below as reported by the employees:

"lack of social relations with colleagues"

"lack of adequate technologies"

"difficulties in communicating with colleagues to discuss work, or missing information"

Based on the comments reported, many employees perceived experiences of social isolation and loneliness, difficulty in disconnecting from technology which led to insufficient free time, inadequacy of the tools which affected the SW experience, inadequate communication with managers which led to feelings of distrust. All this led the employees to express the need for future structured and well-organized SW, providing adequate tools, evaluating performance on the basis of objectives, implementing a clear communication of information.

Furthermore, health conditions during SW throughout the Covid-19 pandemic significantly worsened compared to the previous period, especially with regard to anxiety, sleep, and emotional symptoms, for specific and broad segments of the working population.

\section{Discussion}

The data clearly show the complexity of analyses and interventions in relation to the SW phenomenon. The protection of employees' health, especially in terms of recovery and work-family balance appears to be particularly complex. The problems raised by the research must be answered on various levels, in terms of defining new labor codes and good practices. Such responses will make the difference between good work done in SW and simply carrying out tasks from remote locations. The dimensions, principles, and behaviors constituting the new labor codes are therefore important. Some of them are the consistency of objectives and action procedures, organizational efficiency and effectiveness, organizational well-being and work-related stress, appreciation of employees, and work ethics for the person and the organization. The dimensions indicated above are complemented by various models of good practice, such as the substantial and widespread fairness of the evaluations, the adequate management of relations with colleagues and superiors, the prevention of absenteeism as well as presenteeism, the effective circulation of information, and monitoring and timely process adjustments.

Additionally, to support smart workers, online psychological intervention has become more significant. The development of tools and protocols for psychological support to employees through technology, specifically online and virtual reality services, allows to intervene in the conditions that have arisen in the world of work following the COVID-19 emergency. Online psychology allows to listen to and support employees anytime anywhere. No barrier prevents the organization from supporting employees in SW, protecting their psychophysical health in real time. Through these protocols, the organization can offer listening, professional support, and assistance to employees, helping them cope with potentially problematic and stressful situations, as well as collaborating in resolving any disputes and conflicts.

Today, psychology and technology are at the forefront of overcoming the crisis, providing companies with powerful listening, support, and recovery techniques for everyday critical situations. 


\section{References}

Argentero, P., \& Cortese, C. G. (2021). Psicologia delle risorse umane. Nuova edizione [Psychology of human resources. New edition]. Milano: RaffaelloCortina Editore.

Bozzaotra, A., Cicconi, U., Di Giuseppe, L., Di Iullo, T., \& Manzo, S. (2017). Commissione atti tipici, osservatorio e tutela della professione. Digitalizzazione della professione e dell'intervento psicologico mediato dal web [Commission of typical acts, observatory and protection of the profession. Digitization of the profession and psychological intervention mediated by the web]. Roma: Tipografia Ostiense

Dal Corso, L., De Carlo, A., Carluccio, F., Colledani, D., \& Falco, A. (2020). Employee burnout and positive dimensions of well-being: A latent workplace spirituality profile analysis. PLoS ONE, 15(11), Article e0242267

De Carlo, A., Dal Corso, L., Carluccio, F., Colledani, D., \& Falco, A. (2020). Positive Supervisor Behaviors and Employee Performance: The Serial Mediation of Workplace Spirituality and Work Engagement. Frontiers in Psychology, 11, Article 1834

De Carlo, A., Girardi, D., Falco, A., Dal Corso, L., \& Di Sipio, A. (2019). When does work interfere with teachers' private life? An application of the job demands-resources model. Frontiers in Psychology, 10, Article 1121

De Carlo, N. A., \& Maccani, I. (2021). Codice Smart Working [Smart Working code]. Trento: SEAC.

De Carlo, N. A., Falco, A., \& Capozza, D. (2013) (a cura di). Stress, benessere organizzativo e performance. Valutazione \& intervento per l'azienda positiva [Stress, organizational well-being, and performance. Assesment $\&$ intervention for the positive organization]. Milano: FrancoAngeli.

Di Sipio, A., Falco, A., Kravina, L., \& De Carlo, N. A. (2012). Positive personal resources and organizational well-being: resilience, hope, optimism, and self-efficacy in an Italian health care setting. TPM - Testing, Psychometrics, Methodology in Applied Psychology, 19(2), 81-95. doi:10.4473/TPM19.2.2

Dimitrova, V. E. (2019, March). The impact of coaching on the emotional intelligence of managers in the organization [Paper presentation]. International Conference on Creative Business for Smart and Sustainable Growth - CreBUS 2019, Article 8840019

Donaldson-Feilder, E., Yarker, J., \& Lewis, R. (2011). Preventing Stress in Organizations: How to Develop Positive Managers. John Wiley and Sons Ltd.

Kaneklin, C., Piccardo, C., \& Scaratti, G. (2010). La ricerca-azione. Cambiare per conoscere nei contesti organizzativi [Action research. Change to know in organizational contexts]. Milano: RaffaelloCortina Editore.

Legge 22 maggio 2017, n. 81. Misure per la tutela del lavoro autonomo non imprenditoriale e misure volte a favorire l'articolazione flessibile nei tempi e nei luoghi del lavoro subordinato [Measures for the protection of non-entrepreneurial self-employment and measures aimed at favoring flexible articulation in the times and places of subordinate work].

Lewin, K. (1946). Action research and minority problems. Journal of Social Issues, 2, 34-46.

Li, J., Ghosh, R., \& Nachmias, S. (2020). In a time of COVID-19 pandemic, stay healthy, connected, productive, and learning: words from the editorial team of HRDI. Human Resource Development International, 23(3), 199-207. https://doi.org/10.1080/13678868.2020.1752493

Masterson, C., Sugiyama, K., \& Ladge, J. (2020). The value of 21 st century work-family supports: Review and cross-level path forward. Journal of Organizational Behavior, 42(2), 118-138. doi: $10.1002 /$ job. 2442

O’Boyle, E. H., Humphrey, R. H., Pollack, J. M., Hawver, T. H., \& Story, P. A. (2010). The relation between emotional intelligence and job performance: A meta-analysis. Journal of Organizational Behavior, 32(5), 788.

Reason, P. \& Bradbury, H. (2001). Handbook of Action Research. London: Sage

Richardson, L.K., \& Simpson, S. (2015). The Future of Telemental Health and Psychology in Australia: Restoring the Psychologically "Clever Country"?. Australian Psychologist, 50, 307-310.

World Health Organization (2021). Coronavirus (COVID-19). https://covid19.who.int/ 